\title{
Correlation of Great Saphenous Vein Diameter in Development of Reflux and Varicosity
}

\author{
Mayurika Singh ${ }^{1}$, Sanjay Singh ${ }^{2}$, Anil Kumar Singh ${ }^{3}$, Maha Devan $^{4}$ \\ ${ }^{1}$ Associate Professor, Department of Radiodiagnosis, ${ }^{2}$ Associate Professor, PG Department of General Surgery, ${ }^{3}$ Junior \\ Resident, PG Department of General Surgery, ${ }^{4}$ Junior Resident, PG Department of General Surgery, Moti Lal Nehru Medical \\ College, Allahabad, India
}

Corresponding author: Dr. Sanjay Singh, PG Men's Hostel, Swaroop Rani Nehru Hospital (SRN), Allahabad, India

DOI: http://dx.doi.org/10.21276/ijcmsr.2020.5.1.48

How to cite this article: Correlation of great saphenous vein diameter in development of reflux and varicosityMayurika Singh, Sanjay Singh, Anil Kumar Singh, Maha Devan. International Journal of Contemporary Medicine Surgery and Radiology. 2020;5(1):A224-A227.

\section{A B S T R A C T}

Introduction: Varicose vein is a common venous problem usually affecting superficial veins of the lower limb and characterized by prominent vein, swelling, itchiness, pigmentation, and ulcer. Venous insufficiency can arise from obstruction, such as in the case of deep vein thrombosis (DVT) or valve incompetence as in saphenous reflux or post thrombotic syndrome.

Material and methods: The present study was carried out on 43 patients attending the outpatient and inpatient of Swaroop rani hospital, Department of General surgery and department of radiology over a period of 12 months. A written informed consent was obtained from all subjects prior to the performance of study related procedure.

Results: Majority of patients in both the groups were males, in the age group of 21-40 years. Most patients presented within 5 years of developing the disease. Both the limbs had equal incidence of disease occurrence. Most common symptom was swelling of limbs in $48.15 \%$ patients. Long duration of standing more than 8 hours was found to be significantly related to development of varicosity ( $p$ value= 0.0016 ). Mean great saphenous vein diameter was $6.91 \pm 0.579$ in the study group.

Conclusion: we conclude that occupations involving prolonged periods of standing are the major contributing factors for prevalence of varicose veins. Also, increasing diameter of great saphenous vein is directly related to development of reflux and varicosity.

Keywords: Great Saphenous Vein Diameter, Development of Reflux, Varicosity

\section{INTRODUCTION}

Chronic venous disease (CVD) is defined as abnormal functioning of the venous system caused by venous valve incompetence, which may affect the superficial or deep venous system or both. Limbs with CVD should be classified according to the CEAP system. ${ }^{1}$ The seven categories of clinical classification are based on objective signs of CVD that are universally recognised. ${ }^{2}$ Venous insufficiency can arise from obstruction, such as in the case of deep vein thrombosis (DVT) or valve incompetence as in saphenous reflux or post thrombotic syndrome.

Varicose vein is a common venous problem usually affecting superficial veins of the lower limb and characterized by prominent vein, swelling, itchiness, pigmentation, and ulcer. The prevalence of varicose vein in studies has shown to range from $5 \%$ to $30 \% .{ }^{3}$ Obesity, age, parity, standing for long times, and family history are risk factors. Many patients undergo treatment of varicose veins for cosmetic reasons, other indications are edema of limb, difficulty in walking, pigmentation and non-healing ulcer. ${ }^{4}$ The introduction of non-invasive methods for preoperative evaluation of varicose veins, such as hand-held Doppler (HHD) and duplex ultrasound has been associated with marked changes in the diagnosis and planning of treatment as compared with clinical assessment alone. ${ }^{5}$ Currently, colour flow duplex scanning is considered the gold standard for non-invasive anatomical and functional assessment of venous reflux (Dixon 1996).

The aim of this study was to investigate the correlation between great saphenous vein reflux and diameter change $2 \mathrm{~cm}$ below from saphenous femoral junction, to evaluate the best cutoff value for great saphenous vein diameter for predicting reflux and to analyze the various risk factors associated with varicose vein.

\section{MATERIALS AND METHODS}

All the cases of varicose vein of lower limb pain symptoms who attended surgical outpatient Department of M.L.N. Medical College, Allahabad, from September 1, 2018 to August 31, 2019 were taken for this study. As soon as patient came with complaints pertaining to peripheral arterial disease, complete history was taken and thorough clinical examination done.

\section{Inclusion criteria}

- Numbness

- Severe Pain

- Non-healing ulcer 
- Discoloration of skin

- Occupation related to long standing

- Varicocele

\section{Exclusion criteria}

- DVT

- Patients who are already diagnosed and on treatment for varicose vein.

- Any pelvic mass with obstructive features/pregnancy

- Non-healing ulcer (traumatic Arterial)

- AV malformation

- Patients with gangrene (dry and wet)

- Coronary heart disease

- Patients unwilling to take part in the study or leaves in between the study.

With duplex scan the inner anechoic diameter of great saphenous vein were measured $2 \mathrm{~cm}$ distal from SFJ.

The diameter was correlated and analysed the relation

\begin{tabular}{|l|c|c|c|c|}
\hline Age group & \multicolumn{2}{|c|}{ Study group } & \multicolumn{2}{c|}{ Control group } \\
\hline & No. & $\%$ & No. & $\%$ \\
\hline $16-20$ & 1 & 3.7 & 1 & 6.25 \\
\hline $21-30$ & 14 & 51.85 & 5 & 31.25 \\
\hline $31-40$ & 9 & 33.33 & 7 & 43.75 \\
\hline $41-50$ & 2 & 7.4 & 1 & 6.25 \\
\hline $51-60$ & 1 & 3.7 & 2 & 12.5 \\
\hline Total & 27 & $32.59 \pm 9.88$ & 16 & $30.437 \pm 6.99$ \\
\hline P value $=0.449$ & \multicolumn{5}{|c|}{ Table-1: Age distribution } \\
\hline \multicolumn{6}{|c|}{} \\
\hline
\end{tabular}

\begin{tabular}{|l|c|c|}
\hline Symptoms & No. & Percentage \\
\hline Prominent vein & 5 & 18.51 \\
\hline Pain and prominent vein & 13 & 48.14 \\
\hline Prominent veins and swelling of limb & 4 & 14.81 \\
\hline Prominent veins with ulcer & 2 & 7.4 \\
\hline Prominent vein with pain and ulcer & 1 & 3.7 \\
\hline Ulcer & 1 & 3.7 \\
\hline Prominent vein: swelling of limb and pain & 1 & 3.7 \\
\hline Bleeding & 0 & \\
\hline Total Table-2: Different symptoms at presentation \\
\hline \multicolumn{3}{|c|}{} \\
\hline
\end{tabular}

\begin{tabular}{|l|c|c|c|c|}
\hline Vein & Normal $(\mathrm{mm})$ & Reflux $(\mathrm{mm})$ & Difference & P-value \\
\hline GSV & $5.03 \pm 0420142$ & $6.91 \pm 0579$ & $1.88 \mathrm{~mm}$ & $<0.0001$ \\
\hline \multicolumn{5}{|c|}{ Table-3: Diameter of the great saphenous vein } \\
\hline
\end{tabular}

between the diameter of great saphenous vein distal to $2 \mathrm{~cm}$ from SFJ and the appearance of clinical symptoms.

At first for several months, we used 4 layer compressive stocking and lifestyle modifications. After 6 months of conservative management the cases who did not improve or deteriorated, went through operative procedure.

\section{RESULTS}

The present study was carried out on 43 patients attending the outpatient and inpatient of Swaroop rani hospital, Department of General surgery and department of radiology over a period of 12 months. There were 27 patients in the study group (M: F 24:3) \& 16 in control group (M: F 14:2), with both the groups containing mainly male patients ( $88.88 \%$ in study group and $87.5 \%$ in control group).

The maximum number of cases were in the age group 21-40 years in both males as well as females according to table 1.

In both males and females in the study, right limb varicosity was common than left limb varicosity; 12 males (50\%) and 2 females $(66.67 \%)$ had right limb varicosity, while 10 had left limb varicosities (M:F ; 9:1) and bilateral in 3 male patients. In this study pain and prominent vein, in the leg was the most common presenting symptom in $13(48.15 \%)$ cases while $5(18.52 \%)$ cases presented with prominent vein (table-2).

The mean diameter of GSV with reflux was $6.91 \pm 0.579$ and this was larger than normal GSV, which measured 5.03 $\pm 0.420 \mathrm{~mm} 0 \mathrm{n}$ average. The diameter difference between the normal and reflux GSV was $1.88 \mathrm{~mm}$ and statistically. significant ( $p$ value $<0.0001)$ (table- 3 ).

ROC analysis for determining the best cut of value for diagnosing reflux. Receiver operating characteristic (ROC)

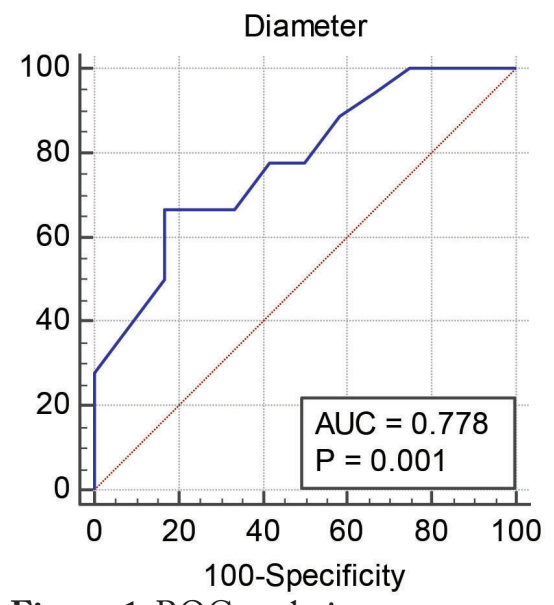

Figure-1: ROC analysis

\begin{tabular}{|l|c|c|c|c|c|l|}
\hline Criterion & Sensitivity & $\mathbf{9 5 \% ~ C l}$ & Specificity & $\mathbf{9 5 \% ~ C l}$ & +LR & -LR \\
\hline$>4.2$ & 94.44 & $72.7-99.9$ & 33.33 & $9.9-65.1$ & 1.42 & 0.17 \\
\hline$>4.3$ & 88.89 & $65.3-98.6$ & 41.67 & $15.2-72.3$ & 1.52 & 0.27 \\
\hline$>4.5$ & 77.78 & $52.4-93.6$ & 50.00 & $21.1-78.9$ & 1.56 & 0.44 \\
\hline$>4.6$ & 77.78 & $52.4-93.6$ & 58.33 & $27.7-84.8$ & 1.87 & 0.38 \\
\hline$>4.7$ & 66.67 & $41.0-86.7$ & 66.67 & $34.9-90.1$ & 2.00 & 0.50 \\
\hline$>4.8$ & 66.67 & $41.0-86.7$ & 83.33 & $51.6-97.9$ & 4.00 & 0.40 \\
\hline$>5$ & 50.00 & $26.0-74.0$ & 83.33 & $51.6-97.9$ & 3.00 & 0.60 \\
\hline$>5.1$ & 38.89 & $17.3-64.3$ & 91.67 & $61.5-99.8$ & 4.67 & 0.67 \\
\hline \multicolumn{7}{|c|}{ Table-4: Criterion values and coordinates of the ROC curve } \\
\hline
\end{tabular}


curve of great saphenous vein (GSV) diameter at $2 \mathrm{~cm}$ below SFJ and varicose vein prediction in male area under the curve: 0.778 cut off of points as $4.8 \mathrm{~mm}$ with sensitivity as $66.67 \%$ and specificity $83.33 \%$.

In the study, cases who stood for more than 8 hours per $\operatorname{day}(\mathrm{n}=25,92.59 \%)$ were more likely to have developed varicosity when compared to cases who stood for less than 8 hours $(n=2,7.41 \%)$ with significant $p$-value of 0.0016 (table-4).

\section{DISCUSSION}

Incidence of varicose veins in adult population has been shown to vary among populations (between 10\% and 60\%) and to increase by age in various studies. ${ }^{6-11}$ Our study consisted of both males and females in both the groups. Number of males was however far higher in both the groups i.e. $24(88.88 \%)$ in study group and $14(87.5 \%)$ in the control group. Males might be more prone to develop chronic venous insufficiency owing to their nature of occupation and longstanding working hours. Obesity and lack of physical activity were strongly associated with CVI in women, more so than in men.

Maximum patients belonged to age groups 21-40 years as most patients presenting to us were occupational workers in this age group and had such nature of their job that required standing for long duration. Majority of the patients developed varicosity in right $\operatorname{limb}(50 \%)$, left $\operatorname{limb}(37.5 \%)$ and bilateral in $12.5 \%$. these findings were compared to Dur et $\mathrm{al}^{12}$ study in which right limb affection was in $48.55 \%$, left limb in $51.45 \%$ and both limbs in $14.28 \%$. Maximum patients presented within 5 years suggesting that development of symptoms due to the disease led them to seek medical attention as this is the duration taken for symptoms to develop which cannot be further tolerated. Engelhorn et al. [13] found that GSV diameter thresholds equal to or greater than 7 mm most accurately predicted reflux. Navarro et al. [14] reported that a GSV diameter of $5.5 \mathrm{~mm}$ or less predicted the absence of abnormal reflux, with a sensitivity of $78 \%$, a specificity of $87 \%$, positive and negative predictive values of $78 \%$, and an accuracy of $82 \%$. A GSV diameter of 7.3 $\mathrm{mm}$ or greater predicted critical reflux with $80 \%$ sensitivity, $85 \%$ specificity, and $84 \%$ accuracy. The mean diameter of the great saphenous vein in normal cases was $5.03 \pm 0.420$ and that in diseases cases was $6.91 \pm 0.579$. The difference in this aspect was found to be statistically significant ( $\mathrm{p}=$ $<0.0001$ ). The diameter measurement has been assessed with different techniques: upright or recumbent patient position and cross sectional or longitudinal imaging. Venous diameter naturally changes according to patient position. The diameter measured in an upright position or upper body elevation will be larger than that measured in a recumbent position. It is warranted that diameter measurement should be done with a consistent method at each vascular laboratory. Upright position was most commonly used to measure the diameter of the saphenous vein [15]. We adopted the recumbent and upright valsalva position.

Most patients presented with limb swelling 13 (48.15\%). Next symptom in presentation was pain or discomfort in the limb present in $5(18.52 \%)$ cases. Mendoza et al. [16] measured GSV diameters at both the SFJ and proximal thigh (15 $\mathrm{cm}$ distal to the groin). They concluded that the GSV diameter correlated with clinical class, with measurement at the proximal thigh being more sensitive and more specific than measurement at the SFJ. venous diameter is significantly related to reflux, as expected. GSV diameter of $\geq 4.8 \mathrm{~mm}$ had the best cutoff value for predicting pathologic reflux.

\section{CONCLUSION}

This study revealed that the disease is more prevalent in the age of 21-40 years. we conclude that occupations involving prolonged periods of standing were associated with varicose veins.

Most of the patients came to the hospital because of swelling or pain in limbs, rather than cosmetic purpose. Increasing diameter of great saphenous vein was directly and significantly related to the development of varicosity. Clinical examination along with duplex sonography was almost confirmative in diagnosis of the disease.

\section{REFERENCES}

1. Wendell-Smith CP. Fascia: an illustrative problem in international terminology. Surgn Radiol Anat 1997;19(2):273-7.

2. Caggiati A. Fascial relationships of the long saphenous vein. Circulation 1999;100(6):2547-9.

3. Caggiati A, Bergan JJ, Gloviczki P, et al. Nomenclature of the veins of the lower limbs: an international interdisciplinary consensus statement. J Vasc Surg 2002;36(4):416-22.

4. Ricci S, Caggiati A. Does a Double Long Saphenous Vein Exist? Phlebology 1999;14(1):59-64.

5. Shebel ND, Whalen CC. Diagnosis and management of iliac vein compression syndrome. J Vasc Nurs 2005;23(3):10-7.

6. A. Rizzi, D. Quaglio, G. Vasquez et al., Effects of vasoactive agents in healthy and diseased human saphenous veins, Journal of Vascular Surgery 1998;28(5):855-861,.

7. S. Meghdadi, M. Rodrigues, A. Oguogho, R. Santler, and H. Sinzinger. 8-Epi-PGF2 $\alpha$ and 6 -oxo-PGF1 $\alpha$ in human (varicose) veins: influence of age, sex, and risk factors. Angiology 2003;54(1):317-324,.

8. A. N. Nicolaides. Investigation of chronic venous insufficiency: A consensus statement. Circulation 2000;102(6):e126-e163,.

9. P. K. Shireman, W. J. McCarthy, W. H. Pearce et al. Plasminogen activator levels are influenced by location and varicosity in greater saphenous vein. Journal of Vascular Surgery 1996;24(3):719-724.

10. J. Golledge and F. G. Quigley, "Pathogenesis of varicose veins," European Journal of Vascular and Endovascular Surgery 2003;25(4):319-324,

11. M. H. Howlader and P. D. Coleridge Smith. Symptoms of chronic venous disease and association with systemic inflammatory markers. Journal of Vascular Surgery 2003; 38(5):950-954.

12. Dur AHM, Mackaay AJC, Raurweda JA. Duplex assessment of clinically diagnosed venous insufficiency. Br Journal of Surgery. 1992;79(5):155-6

13. Engelhorn C, Engelhorn A, Salles-Cunha S, Picheth 
E, Castro Jr N, Dabul Jr N, et al. Relationship between reflux and greater saphenous vein diameter. J Vasc Technol 1997;21(1):167-71.

14. M.V.L Tulio P. Navarro, MD; Konstantinos T. Delis, MSc, MD, PhD; Antonio P. Ribeiro, MD. Clinical and Hemodynamic Significance of the Greater Saphenous Vein Diameter in Chronic Venous Insufficiency. JAMA surgery. Arch Surg. 2002;137(11):1233-1237.

15. Recek C. Calf pump activity influencing venous hemodynamics in the lower extremity. Int J Angiol 2013;22(3):23-30.

16. 1E.Mendozaa, W.Blättlerb, F.Amslerc. Great Saphenous Vein Diameter at the Saphenofemoral Junction and Proximal Thigh as Parameters of Venous Disease Class. European Journal of Vascular and Endovascular Surgery. 2013;45(1):76-83.

Source of Support: Nil; Conflict of Interest: None

Submitted: 16-12-2019; Accepted: 13-02-2020; Published online: 20-03-2020 